\title{
PUBLIC LECTURE
}

\section{METHODOLOGY, THEORETICAL FRAMEWORK AND SCHOLARLY SIGNIFICANCE: AN OVERVIEW OF INTERNATIONAL BEST PRACTICES IN LEGAL RESEARCH}

\author{
Rhuks Ako* \\ Damilola S. Olawuyi**
}

A public lecture delivered at the 48th Annual Conference of the Nigerian National Association of Law Teachers hosted by Afe Babalola University, Ado Ekiti, Nigeria

\begin{abstract}
Communicating the results of painstaking legal research efforts is arguably as important as conducting the research itself. Established international publication outlets apply diverse submission guidelines for prospective authors. One common currency, however, is that getting a research paper from conception to publication, as a journal article, book chapter, or forum paper, requires an author to demonstrate a potential contribution to knowledge in the field. This requires a systematic research approach that unpacks contemporary issues in an analytical manner; a clear and concise presentation of ideas with focus on effectiveness; adoption of tested theoretical frameworks to underpin new ideas; and a careful proofreading of manuscript to ensure that a prospective publication meets the expected standards of good quality contribution to theory, practice or policy. This article discusses the indispensable standards and important guidelines that authors should weigh before writing papers for publication, most especially for internationally recognized journals. The authors draw on their experiences as Editorial Board members of national and international journals to unpack key theoretical, methodological and
\end{abstract}

* Ph.D (Kent), Senior Fellow, Institute for Oil, Gas, Energy, Environment and Sustainable Development, Afe Babalola University, Ado Ekiti. Email: rako@ogeesinstitute.edu.ng.

** LL.M (Calgary), LL.M (Harvard), Ph.D (Oxford), Professor of Law and Director, Institute for Oil, Gas, Energy, Environment and Sustainable Development, Afe Babalola University, Ado Ekiti. Email: dolawuyi@ogeesinstitute.edu.ng. 
practical issues that legal researchers should consider when developing legal research papers.

Keywords: Legal Research, Methodology, Theory, Pedagogy, Legal Training, Scholarship

DOI: https://dx.doi.org/10.4314/jsdlp.v8i2.11

\section{INTRODUCTION: THE SEARCH FOR METHODOLOGY AND THEORY IN LEGAL RESEARCH}

In 1999, the American Journal of International Law, one of the leading journals in international law, organized a symposium to review best practices in legal research. The symposium, amongst other things, decried the falling standard of legal research due to increased lack of attention to methodology and legal theory. ${ }^{1}$ Since 1999, several conferences have been held just as several forests of literature have been produced by legal analysts and scholars on the need for more systematic research and theory-laden publications within tertiary education, the legal profession and the legal education sector. ${ }^{2}$ The requirements for methodology and legal theory have, therefore, found their ways into publication standards and acceptance review requirements of several leading international journals. More than ever before, scholars are expected to demonstrate a thorough, theory-laden and methodological analysis in their research papers, thereby offering significant scholarly contributions to knowledge in their respective fields. Therefore, in pre-selecting papers for publication, many journals adopt relevance to an international audience as a preliminary selection criterion. A relevant paper is one that clearly and concisely unpacks contemporary themes of law using internationally recognized theoretical and methodological frameworks and approaches.

The self-questioning and search for relevance, methodology and theory in legal research is a reflection of the increased internationaliza-

1 Steven R. Ratner \& Anne-Marie Slaughter, "Appraising the Methods of International Law: A Prospectus for Readers" (1999) 93 Am. J. Int'L. 291, 292.

2 See for example, L. Fisher, B. Lange and E. Scotford, "Maturity and Methodology: Reflecting on How to Do Environmental Law Scholarship" (2009) Journal of Environmental Law, 1-38. 
tion of the law. ${ }^{3}$ Globally, the teaching or learning of law has witnessed rapid changes from the 1960s to now. Owing to increased globalization, the borrowing of legal traditions and the legal transplant of laws and institutions from other Commonwealth countries to Nigeria, the teaching or learning of the law has taken a more comparative and international approach. For example, jurisprudence and legal writings in countries such as India, Canada, the United Kingdom and the United States have increasingly shaped how legal concepts such as sustainable development, the duty of care, euthanasia, corporate social responsibility, human rights and negligence are applied and defined in Nigeria. Furthermore, the increased proliferation of organizations and specialized bodies at regional and supra-national levels also has resulted in lawyers being increasingly called upon to argue the law before international bodies and to apply comparative international law in an imaginative manner.

Summarily, students of the law in this century can no longer afford to understand and communicate legal concepts in local and national contexts alone. With more international business and travel and a growing awareness that many socio-economic and environmental problems need global solutions, the future of legal education and research appears to be one of internationalization. This realization has led to increased emphasis on international publications by Nigerian legal scholars. In many Nigerian Universities, law teachers must maintain a robust track record of publications in international journals as a precondition for promotion and tenure. To develop an impressive publication track record necessary for tenure and promotion, scholars of today must not only conduct research, they must also demonstrate relevance and communicate research results in a manner that is understood and appreciated by readers locally, nationally, regionally and across the globe.

Contrastingly, however, an increasing number of legal researchers have struggled perennially to meet the litmus test of theoretical and methodological relevance. This is arguably due to the prevailing unsophisticated understanding of legal research expectations and approaches. The relevant question is: what are the expectations of a law journal and how does it select what to publish? The lack of sophisticated understanding of these questions is arguably due to the

3 R. Cryer, T. Hervey and B. Sokhi-Bulley, Research Methodologies in EU and International Law (Hart Publishing 2011) 5. 
age-long simplistic assumptions that have shaped legal curriculum development and training in Nigeria: that law students do not need much research training beyond an introduction to legal sources. This fallacious assumption arises first from the underlying legal training paradigm and perceptions in many law faculties and the Nigerian Law School that law students are being trained primarily to become practising lawyers. This assumption flies in the face of statistics which shows that only 20 per cent of LL.B graduates in Nigeria stay on to practice the law after being called to the Bar. ${ }^{4}$ Others go into law teaching, policy analysis, consultancy, politics, accounting, fashion and, increasingly these days, music and acting. ${ }^{5}$ The prevailing legal curriculum and teaching paradigm in Nigeria which tends to focus more on assimilating the law, and less on writing, analysing or researching the law often fail lawyers who find themselves outside of core legal practice. Legal researchers and teachers arguably fall into this category.

For example, I recall struggling greatly as a Master of Laws (LL.M) candidate, when my instructors increasingly demanded that I apply "more theory and methodology to my research" as I could not initially grasp the meaning of those words. This is because prior to my LL.M programme, the only extensive legal research paper I had ever written was my LL.B thesis, which did not have extensive requirements to understand or apply any "theory and methodology to my research". Making the transition from a "read, assimilate and pass-focused training" that I gained in the Bachelor of Laws (LL.B) and the Nigerian Law School, to more of "research and analysis-based expectations" in the LL.M was therefore exceedingly tasking and herculean. This story demonstrates that the prevailing legal practitioner model of legal training in Nigeria that focuses less on research and analytical skills, and assumes that doctrinal skills would be naturally picked up by law graduates requires a rethink. There is a need for a more sophisticated understanding of research expectations, methodology and theory at

4 This issue was raised at the International Association of Law School's 2nd Annual African Law Deans' Forum, (Law School Leadership in the 21st Century: Meeting the Global Challenge held on 10 \& 11 June 2013 at the University of Nigeria, Enugu) < http://www.ialsnet.org/wordpress/wp-content/uploads/2013/06/ 2013-African-Deans-Forum-Packet-FINAL-060413.pdf> accessed 10 May 2015.

5 Richard Mofe Damijo and Funke Akindele are two of the famous actors who had legal training and were called to the Nigerian Bar. Also, Tara Fela-Durotoye, the Chief Executive Officer of House of Tara International, is a law graduate turned make-up artiste. 
all levels of legal training in Nigeria. This higher level of understanding must place more emphasis on research, analysis, theory and methodology to equip law graduates and prepare them adequately for an increasingly globalized and international legal job market.

An enquiry and search for methodology and theory in legal research raises four preliminary issues: (i) What is the meaning of legal research and what is its nature? (ii) What is methodology? (iii) What is legal theory? and (iv) How is a methodological and theory-laden research paper best achieved? The aim of this article is to unpack and discuss these four key questions. The purpose of this analysis is to highlight the importance of carefully selecting and adopting appropriate methodologies and theory when developing research papers, articles, research critiques, book chapters, or forum papers. The presenters draw on their experiences as Editorial Board members of leading national and international journals to unpack key theoretical, methodological and practical issues that legal researchers should carefully consider when developing legal research papers and before putting pen to paper.

This article is divided into six sections. After this introduction, section 2 discusses the meaning and nature of legal research. The section focuses attention on the question: what is legal research and how is this different from research in other social sciences or the humanities that it requires theories and methodologies? Section 3 examines the role of methodology in legal research and the meaning and nature of methodology. Theoretical self-consciousness in legal research requires a deep-rooted understanding of diverse theoretical models in legal research. Section 4 discusses the importance of situating research ideas and arguments in established legal theories such as the: natural law, legal positivism, cosmopolitanism, constitutionalism, queer theory, feminism, Third World Approaches to International Law (TWAIL), comparative law and legal transplant theory, postcolonial theory, Marxism, and also Law and Economics, Law and Literature, and Law and Sociology.

It will examine why the application of theoretical approaches to research will not only result in organized and systematic research but also break down notional communication barriers and allow scholars to situate reform proposals in tested and globally understood theoretical models. Section 5 discusses how effective methodological and theory-laden research papers may best be achieved. It will highlight and recommend successful methods and international best practices that research professionals use effectively to communicate research 
results and to achieve greater publication acceptance ratios in leading journals and academic press. Section 6 presents our conclusions.

\section{MEANING AND NATURE OF EFFECTIVE LEGAL RESEARCH}

Research is any creative work undertaken on a systematic basis to increase knowledge. ${ }^{6}$ The ultimate purpose of legal research, therefore, is to unearth legal solutions to complex legal problems. Through legal research, scholars can establish or confirm facts, reaffirm the results of previous work, solve new or existing problems, support or critique existing legal theories or develop new theories. ${ }^{7}$

Legal research has been categorized into four broad headings. ${ }^{8}$ First is the doctrinal research, which provides a systematic exposition of the rules governing a particular legal category, analyses the relationship between rules, explains areas of difficulty and, perhaps, predicts future developments. Second is the reform-oriented research, which intensively evaluates the adequacy of existing rules and recommends changes to any rules found wanting. Third is theoretical research, which fosters a complete understanding of the conceptual bases of legal principles and of the combined effects of a range of rules and procedures that touch on a particular area of activity. Fourth is fundamental research, which is designed to secure a deeper understanding of law as a social phenomenon, including research on the historical, philosophical, linguistic, economic, social or political implications of law. ${ }^{9}$

While a research paper could be structured to achieve any of the above diverse aims, an effective legal research discusses and reviews a problem, provides succinct historical backgrounds to enable diverse readers to understand the scope of the problem and then propounds

6 See J. Creswell, Educational Research: Planning, Conducting, and Evaluating Quantitative and Qualitative Research (3rd ed. Pearson, 2008).

7 According to Jan Smits answering normative legal questions is what law as a science should be about. Everything else he sees as a by-product or as non-legal research. See J.M. Smits, "Redefining Normative Legal Science: Towards an Argumentative Discipline" in F. Coomans, F. Grünfeld, M. Kamminga (eds.), Methods of Human Rights Research (Maastricht Series in Human Rights 2009), 45-58.

8 These definitions are as excellently presented in D. Pearce, E. Campbell and D. Harding ("Pearce Committee"), Australian Law Schools: A Discipline Assessment for the Commonwealth Tertiary Education Commission (1987), 307-308.

9 ibid; T. Hutchinson, Developing Legal Research Skills: Expanding the Paradigm (2008), 32 Melbourne University Law Review 1065-1095. 
legal reform suggestions or solutions to the problem. A cursory reading of an effective paper should reveal its aim and approach. It is often a painful experience and arguably a patent indication of ineffectiveness for a reader to wait for more than two pages to be able to tell why they should read further. Furthermore, the aim of research is to increase knowledge. Therefore, a paper that merely summarizes or provides historical homilies, axiomatic discourses or presents plenitude of definitions of legal concepts, with little or no analysis to move the understanding or application of such concepts forward, are often perceived as descriptive, pedestrian and irrelevant and are typically marked for rejection in any scholarly journal worth its name.

The process of achieving an analytical and effective paper can be explained by borrowing analogies from the scientific world. In the sciences, every ground-breaking discovery starts with a hypothesis which means a scientific guess, or simply defined a suggestion that can be supported or refuted through carefully crafted experimentation or observation. A truly analytical legal paper, just like many scientific works, starts with a hypothesis which is often summarized in the aim of the paper. An example of a legal hypothesis would be for a researcher to nurture the idea of proposing an amendment of the Constitution to move environmental rights into the justiciable portions of the Constitution.

The second stage is to test the hypothesis. At this stage, a hypothesis moves through sustained and theoretical analysis, which is an attempt to find "authority" that supports the hypothesis. In legal research, this is the stage where a researcher is expected to answer the question of why. As Rob van Gestel, et al. righty notes, "We feel that in the end the attention for the 'why questions' in legal research is what really distinguishes legal scholars from practitioners."10 Nicholas Hancox also rightly notes that answering the question of why is what distinguishes academics from barristers and solicitors:

academic lawyers want to understand the way that law works and how it affects people and organizations, but practitioners are not interested in why the law says what it says. ${ }^{11}$

To answer the question of why, a paper must painstakingly analyse

10 R. van Gestel, H. W. Micklitz \& M. Poiares Maduro, "Methodology in the New Legal World" (EUI Working Paper Law 2012/13) 5.

11 M. McConville and W. Hong Chui (ed.), Research Methods for Law (Edinburgh University Press 2007) 2. 
diverse theories, debates, arguments, statutes, regulations, court orders, and court decisions in the field that could lend credence or support to the idea under review; and will also respond to opposing theories that may not support the view. Using our earlier example, at this stage a researcher will review debates on the need to constitutionalize environmental rights and why placing environmental provisions in justiciable sections is the better view.

When the hypothesis is sufficiently underpinned and supported by established theories, it then moves to become a theory. A theory is a confirmed or proven hypothesis. It is a well-substantiated explanation of why things should be done in a certain way acquired through scholarly analysis and testing. We, therefore, agree with Rob van Gestel, et al. that:

Students who claim they have a "theory" at the start of their $\mathrm{PhD}$ often mean they have a hypothesis (which is usually kept implicit) or a hunch about the most likely answer to the research question. ${ }^{12}$

A research paper could be very short but most effective if it demonstrates the above systematic transition from hypothesis to analysis and then to theory. A legal research paper contributes to knowledge by offering a well-substantiated explanation of why things should be done a certain way. In our previous example, the theory stage is where the researcher having established that moving environmental provisions to become justiciable is the way forward, will propound recommendations and reform proposals on how to achieve such amendments.

To ensure focus and coherence, a systematic paper must carry the hypothesis all through the paper. Straying into discussions and debates that do not test the hypothesis or add to the subject under discussion significantly diminishes the overall significance and relevance of a paper. ${ }^{13}$ At every stage of the paper, from abstract to conclusion, the underlying goal must be to present systematic and sustained analyses of the subject matter.

12 R. van Gestel, H. W. Micklitz \& M. Poiares Maduro (n 10) 4.

13 See Council of Australian Law Deans ("CALD"), The Research Quality Framework (RQF): Responses to the Issues Paper (2005) < http://www.dest.gov.au/NR/ rdonlyres / 62C38170-6F41-45F1-9180-D0065FB33089/6011/ RQF010117CALD.pdf $>$ accessed 12 May 2015. 


\section{IMPORTANCE OF METHODOLOGY IN LEGAL RESEARCH}

Legal research and its results were once described in such unflattering terms that would dissuade many from engaging in research, especially if the comments still ring true almost half a century since the observation was made. According to Becher, academic lawyers were regarded as "not really academic ... arcane, distant and alien: an appendage to the academic world ... vociferous, untrustworthy, immoral, narrow and arrogant" and their research "unexciting, uncreative, and comprising a series of intellectual puzzles scattered among large areas of description". ${ }^{14}$ There are several reasons that may have founded, or contributed, to the above criticism of legal doctrine. In the words of Van Hoecke:

Of course, the criticism of legal doctrine is partly founded: it is often too descriptive, too autopoietic, without taking the context of the law sufficiently into account; it lacks a clear methodology and the methods of legal doctrine seem to be identical to those of legal practice; it is too parochial, limited to very small scientific communities, because of specialisation and geographical limits; there is not much difference between publications of legal practitioners and of legal scholars. ${ }^{15}$

If a key criticism of legal research is its failure to have a clear methodology and methods, it is essential that all legal researchers have an understanding of what these terms mean and how they can contribute to the shaping and enhancing of the quality of their research.

The methodology of a discipline gives an account of successful methods and best practices used by professionals in the field to conduct research and to communicate research outcomes. ${ }^{16}$ Methodology is

14 T. Becher, "Towards a Definition of Disciplinary Cultures" (1981) Studies in Higher Education 6, 111.

15 M. Van Hoecke, "Legal Doctrine: Which Method(s) for What Kind of Discipline?" in M. van Hoecke (ed.), Methodologies of Legal Research: Which Kind of Method for What Kind of Discipline? (Hart Publishing 2011) 3.

16 R. Cryer, T. Hervey and B. Sokhi-Bulley, Research Methodologies in EU and International Law, (Hart Publishing 2011) 5; B. van Roermund, "Theory and Object in Law: the Case for Legal Scholarship as Indirect Speech", in M. van Hoecke (ed.), Methodologies of Legal Research: Which Kind of Method for What Kind of Discipline? (Hart Publishing 2011) 277. 
the basis for the adoption of a method, with "method" defined by Van Roermund as a road to the solution of a problem or a set of problems. ${ }^{17}$ Van Roermund infers from the above that, in law, methodology is a back-and-forth between actual practice in legal scholarship and rather abstract philosophy. ${ }^{18}$ While the above definition gives an indication of what methodology means, it is trite to note that in legal scholarship, the term has multiple meanings. This situation is quite unlike other disciplines such as within the social sciences, for instance, where it connotes following philosophical assumptions that underlie a study. In law, methodology may refer variously to "the way a judge decides a case, how a legal scholar writes a case note or an article, of the way the discipline as such discerns between different types of legal research (e.g. socio-legal versus doctrinal), or how a certain school of thought presents itself to the research community (new legal realism or critical legal studies)". ${ }^{19}$ Elsewhere, methodology, at least within the context of international law, is defined as being representative of "the application of a conceptual apparatus or framework - a theory of international law - to the concrete problems faced in the international community." 20 In other words, methodology refers to the interrogation of practical issues or questions based upon theoretical foundations. In the realm of legal scholarship, methodology is "more concerned with making implicit assumptions explicit, with research design, and consistency between questions, data, skills and techniques to analyse these data, and the care for consistency between questions, data, methods, and conclusion". ${ }^{21}$ In other words, legal scholarship revolves around methodology.

Moving beyond the realm of the conceptual discourse of "methodology", it is important to highlight some of the key features or imperatives of sound research methodology. There are three basic elements that underpin sound research methodology. These are the research question, the research method, and the theoretical framework. The fundamental issue regarding the research question is that it must be viable. Not all topics are "researchable" - for different reasons.

17 Ibid.

18 Ibid.

19 R. Van Gestel, H Micklitz and M Maduro (n 10).

20 S. Ratner and A. Slaughter, "Appraising the Methods of International Law: A Prospectus for Readers" (1999) 93 Am. J. Int'L., 291, 292.

21 R. Van Gestel, H. Micklitz and M. Maduro (n 10). 
Sometimes, it could be because the question is too narrow (or too wide) or the proposal does not have the potential to add anything novel to extant literature/knowledge. Something that comes to mind on research question in Nigeria is the tendency for academic outputs journal articles, PhD theses and even books - to be a "critical analysis" of something or the other. Thus, there are numerous projects that critically analyse the same subject without a differentiation in methodology; hence lacking any real contribution to knowledge. While there is nothing ostensibly wrong with critically analysing legislation or even a court's decision, the question to ask is "to what end"? Why are we engaging in the critical analysis? What is the foundation of the analysis? Often times, the analysis is limited to "commentaries" on the legislation or decision in issue without any theoretical foundations that inform such criticisms.

From experience, scholarly engagement with so much "critical analysis research" or "commentary-based" research is a reflection of the gap in knowledge on methodology and perhaps the over-emphasis placed on our training in doctrinal legal research (or black-letter law). Scholars tend to interpret the law without digging deeper to ask the why question. An example that comes to mind to highlight this point is the plethora of literature written on the Land Use Act, most of which recommend the amendment or repeal of the Act. While all the arguments tend to highlight the perceived negative impacts the law has on the different segments of the citizenry, very few have hinged their arguments on a sound methodology. In other words, not many have asked the why question while also aiming to provide answers to the how questions that arise. For instance, what is the theoretical basis upon which it is argued that the law is unfair? In other words, why is it unfair? How it is unfair will be a reflection of the practical realities of the impacts of the law as reflected by the theoretical underpinnings. It is in this sense that Van Roermund defines methodology as "a back-and-forth between actual practice in legal scholarship and rather abstract philosophy". ${ }^{22}$

The method of research is dependent on the type of research in question. There is a wide variety of methods applicable, ranging from doctrinal to empirical, expository, analytical, theoretical, comparative, and multi-disciplinary to mention a few. No method ranks higher in quality than the others, and the choice a researcher makes should ideally

22 B. van Roermund (n 16). 
be based on two primary considerations - the research question and the preference of the researcher. The latter is not an excuse for researchers to indulge in purely "commentary writing" and claim this is their preferred "research" method. Rather it is an opportunity for intellectual reflection to determine what option is best within practical limitations. In other words, it entails a considerable level of pragmatism. For instance, it will prove an onerous task, if not an impossible one, to engage in quantitative research without research funding as the getting the requisite numbers of subjects for research will necessarily require substantial financial resources. Similarly, engaging in quantitative research without having gone through prior training in the method and/or the use of IT software will face the same fate.

While there are various methods, none is superior, but each one is different and more suitable or adaptable to particular types of research, usually indicative of the research question. While some research questions will be satisfied with adopting a doctrinal approach, others may require some theoretical underpinnings and others need empirical evidence. Of course, it is also not simply a case of one or the other, as many research endeavours will require a blend. This is more so that contemporary academic research has moved towards multidisciplinary/ interdisciplinary endeavours. This is particularly evident in the funding calls from major funders that clearly have a preference for research that is multidisciplinary, including team members from a wide range of disciplines. What this portends for researchers is the ability to tap into the expertise of colleagues from other disciplines that may have the requisite acquired knowledge through formal training and/or practical experience in certain research methods.

For instance, the social sciences are more adept at gathering empirical data while colleagues in philosophy are more likely to be in tune with theoretical frameworks. The suggestion here is not that legal academics should leave work on their methods to others. Rather, the point being made is that legal training in Nigeria - academic and professional - must prepare us for a doctrinal method of research, such that by collaborating with colleagues from other disciplines, we are able to expand insights into other research methods. In essence, the multidisciplinary approach to research has opened the doors of "methodology" beyond the traditional legal application. It is left to legal academics to get beyond their "traditional" research that was (and remains so in Nigeria) heavily restricted to the analysis of case law, legislation and other legal documents that may have remained 
outside the appreciation of "mainstream" researchers.

While this kind of analysis in socio-legal research (without theoretical basis) is criticized as "hollow", it is noteworthy that theoretical research without any empirical content is considered equally hollow. ${ }^{23}$ Essential in this respect is that methodology should not be seen as something that is imposed upon legal scholars by others but as a voluntarily chosen modus operandi that can make one's research more challenging, more valid, and more credible. ${ }^{24}$

\section{LEGAL THEORIES}

In the discourse on the need for applying legal theories, finding an acceptable definition for legal theory itself has always been a daunting task. ${ }^{25}$ Legal theories are generally a coherent group of tested and wellelaborated propositions that can be used as principles of explanation and support for a legal question or problem. Well-tested and commonly applied legal theories include natural law, legal positivism, cosmopolitanism, constitutionalism, queer theory, feminism, Third World Approaches to International Law (TWAIL), comparative law and legal transplant theory, postcolonial theory, Marxism, and also Law and Economics, Law and Literature, and Law and Sociology.

An enquiry into the importance of applying legal theories in research begins with Oliver Wendell Holmes's age-long prescription that legal reasoning should be concerned with providing reasons that refer to the social ends of law. ${ }^{26}$ Testing a research proposal or idea involves analysing reasons why a proposal should be viewed as falling within the aims and limits of the law. Theories provide pillars - whether explanatory, justificatory, or reformist - that offer contextual insights on the sources and evolution of the proposal; and reasons why the proposed idea may achieve eventual adoption and acceptance. ${ }^{27} \mathrm{~A}$ systematic paper, therefore, seeks to contextualize and underpin

23 R. Van Gestel, H. Micklitz and M. Maduro (n 10).

24 ibid.

25 For an excellent historical account, see Philip Soper, "Legal Theory and the Problem of Definition" (1983) 50 (3) Chicago Law Review, 1170-1200.

26 Oliver Wendell Holmes, "The Path of the Law" in Collected Legal Papers (1920), 167, 184.

27 See Hanoch Dagan \& Roy Kreitner, "The Character of Legal Theory" (2011) 96 Cornell Law Review 685. 
proposals within contemporary theories, debates and well-elaborated general propositions. Apart from demonstrating relevance, underpinning research papers by legal theories also breaks down communication barriers and aids the better understanding of origins and normative strengths of a proposal.

While we do not suggest here that all papers must be theory-laden to be effective, researching theoretical approaches and perspectives in a given field saves a researcher the labour of thoughts and also provides conceptual pillars and frameworks that might guide a research idea to a logical and coherent end.

\section{GETTING IT RIGHT: SOME PRACTICAL GUIDELINES}

With the publication of articles, particularly in reputable international ones in more recent times, being a key element for recognition among peers and university administrations, it has become imperative for legal academics to have outputs of good quality and quantity. However, for a paper to be considered for publication by reputable journals, it must be relevant and of good quality. Scholarly relevance and quality of a paper are determined by the contribution the paper makes to the body of literature in the field, its methodological and theoretical approach as well as its presentation. This section is concerned with the latter, having discussed elements of the prior issues in earlier sections of the article.

The presentation of the paper generally refers to its organization, including the title, format, language, writing style and citation of legal authorities. The title of a paper is just as important as its contents the more catchy and apt it is, the more likely it will receive attention. The title should not only entice potential editors and readers; it must succinctly capture the essence(s) of the paper. For instance, a piece titled: "Bureaucratic Rhetoric of Climate Change in Nigeria: International Aspiration versus Local Realities" that discusses the Federal Government's attitude to gas flaring in Nigeria is more likely to receive attention than if it was titled "A Critical Analysis of Gas Flaring Legislation in Nigeria". Where an abstract is required, it should be a short exposition of the background to the paper, the key arguments that it aims to advance and conclusion(s). With an abstract, the key word is brevity. The abstract should not be regarded as a brief introduction to the paper. Where express instructions are not given for 
the length of the abstract, less should be considered more.

The introduction should provide the background to the research topic, the questions the papers intends to address and how it does so. The main body of the paper should be structured in a way that the arguments are logical. New arguments should begin a new section or paragraph as much as is possible. The first sentence should state the main point posited and then be followed by arguments. Statements that are assertive must either have a reference that supports it or arguments that (logically) lead to it. Regarding references, it is not the case that the more references contained in a paper, the less "original work" there is. Experience reveals that not only do colleagues suffer this malaise of thought but it has also affected those that come through the Nigerian education system. A considerable number of Nigerian students in foreign universities tend to struggle earlier on in their studentships with issues of plagiarism and other "unfair academic practices". Providing as many citations as possible could avoid this perception. Furthermore, the conclusion of a paper should not recount arguments already advanced in the body of the paper. The conclusion should ideally reflect the introduction. It should highlight how the paper has delivered its promise, i.e. how questions the introduction averred the paper would answer have been answered and the impacts of the "answers".

Similarly, the observation that Nigerian English is not an internationally recognized language should be remembered at all times. Scholarly writings that embed colloquialism, normative undertones or local parlance leave many editors (especially foreign ones) clueless as to what the writer is trying to say. Effective papers strive to communicate effectively, efficiently and without unnecessary verbosity or grammatical show-off.

Furthermore, proofreading a paper to eliminate mundane typographical errors is important and worthwhile even if there is a financial cost to it. Papers sometimes get rejected by reputable journals because the language is not understood. Having done innumerable reviews for some well-respected journals, the challenge to bring papers with a promise to the level expected for publication is sometimes more arduous than having to write one from scratch. Closely related to the above is the lack of respect for established citation formats. Journals have formats and where papers submitted do not follow their standard format, it is more likely than not to be summarily rejected.

Finally, to gain fresh ideas that stimulate innovative research, it is 
important for scholars to stay closely connected to legal epistemic communities. ${ }^{28}$ As law teachers, staying in touch with our epistemic communities includes joining reputable international organizations such as the International Law Association (ILA) and the Nigerian Society of International Law amongst others that provide tailored opportunities for scholarly dialogue and exchange and also organize global conferences and events where best practices are disseminated. Standing aloof from epistemic research communities is arguably a recipe for staleness and idea-freeze.

\section{CONCLUSION}

Disseminating results of scholarly research in leading publication journals and books is often a rewarding experience for scholars, and has increasingly become a prerequisite for tenure, academic promotion and recognition. As discussed in this article, getting the "yes" from publication outlets however requires a systematic research approach that unpacks contemporary issues in an analytical manner, adopts tested theoretical frameworks to underpin new ideas, clearly and concisely presents ideas with focus on effectiveness, and carefully proofreads final manuscripts to ensure that a prospective publication meets the expected standards of good quality contribution to theory, practice or policy.

To achieve relevance and quality in legal research, it is important for scholars to engage in self-questioning on the what, why and how, before putting pen to paper: what is the problem under review; why is the discourse provided important to resolving the problem; and how can the proposal be implemented or understood.

Lastly, as law teachers, we have eminent roles to play in integrating and mainstreaming international best practices on relevance, methodology, and legal theory into legal education. Legal research training can no longer be wrapped within prevailing practice-focused paradigm. Legal research is a threshold skill that must be continually

28 An epistemic community is a network of professionals with recognized expertise in a particular domain, and an authoritative claim to knowledge within that domain. They have a shared set of normative beliefs, shared causal beliefs, shared notions of validity, and a common policy enterprise. See P. Haas, "Introduction: Epistemic Communities and International Policy Coordination" (1992) 46 International Organization, 1-35. 
developed and passed on to students; students must from day one be trained on how to formulate a proper legal research problem, how to conduct a literature review, how to adopt methodologies and how to apply theoretical frameworks. By so doing, students will be equipped to conduct research and communicate research results in a manner understood and appreciated by readers locally, nationally, regionally and globally. 